\title{
MIELOPATIA POR HTLV-I: UMA DOENÇA SISTÊMICA
}

\author{
AILTON MELO*, IRENIO GOMES*, KILMA MATTOS*
}

\begin{abstract}
RESUMO - A descoberta da associação entre paraparesia espástica tropical e o protovírus T-linfotrópico humano determinou a verificação da existência de uma endemia infecciosa com comprometimento neurológico caracterizado por acometimento de todo o sistema nervoso e por envolvimento de múltiplos órgãos. A característica sistêmica dessa patologia manifesta-se por lesões de órgãos distintos como pulmão, pele e fígado, entre outros. Provavelmente, o quadro clínico pleomórfico dessa doença se deve a co-fatores ainda não esclarecidos.
\end{abstract} tropical.

PALAVRAS-CHAVE: HTLV-I, leucoencefalomieloneuropatia, doença sistêmica, paraparesia espástica

\section{HTLV-I associated myelopathy: a systemic disease}

SUMMARY - Chronic myelopathy associated with T-lymphotropic virus type I (HAM) has been described as an endemic disease in several areas of the world mainly in Asia, Africa and Latin America. The involvement of the central and the peripheral nervous system by HTLV-I observed in South America and Africa points out that this disease is a leukoencephalomyeloneuropathy. Several authors reported involvement outside the nervous system (as uveitis, lymphocytic alveolitis and arthritis, among others) in patients with HAM. In this paper we emphasize that HAM is a systemic disease whose cofactors determine the clinical picture in each patient.

KEY WORDS: HTLV-I, leukoencephalomyeloneuropathy, systemic disease, tropical spastic paraparesis.

A descoberta da associação entre paraparesia espástica tropical e infecção por HTLV-I ${ }^{1}$ veio solucionar um problema diagnóstico que preocupava principalmente os neurologistas da África, América Central e América Latina, em cujos países ainda se apresentam grande número de mielopatias e mieloneuropatias parasitárias e por déficits nutricionais, além de apresentarem endemicidade para HTLV-I ${ }^{1,6,10,13,14}$. Este periódico tem mostrado a associação de acometimento neurológico em pacientes com infecção por HTLV-I que varia de mielopatia ${ }^{4}$ a leucoencefalomieloneuropatia, como demostram as lesões encefálicas periventriculares, subcorticais e medulares encontradas na ressonância magnética ${ }^{7}$ que se somam a comprometimento de nervos periféricos em pacientes da África e América Latina ${ }^{4,10}$.

Antes da descoberta que o HTLV-I estava associado a comprometimento neurológico, já era conhecida sua associação com leucemia/linfoma de células $\mathrm{T}$ adulto ${ }^{15} \mathrm{e}$, posteriormente, alguns autores demonstraram que o acometimento em conjunto do sistema nervoso e hemático era raro porém existente $^{2}$. A investigação sistemática de pacientes com mielopatia por HTLV-I (HAM) veio demonstrar que a patologia não se restringe apenas ao sistema nervoso estando associada a alveolites, artrites, hepatites, Sjögren, síndrome de CREST, ictiose, vasculites, uveítes e meningites, entre outras entidades $^{2,5,11,12}$. Assim, a infecção por HTLV-I pode assumir diferentes manifestações clínicas, as quais dependem de co-fatores não estudados de forma adequada até o momento. Esses co-fatores provavelmente desencadeiam uma reação imunológica que, em indivíduos com determinada condição gênica, predispõe ao aparecimento da sintomatologia.

*Unidade de Neuroinfectologia, Universidade Federal da Bahia (UFBA). Aceite: 5-dezembro-1993.

Dr. Ailton Melo - Unidade de Neuroinfectologia, Faculdade de Medicina, UFBA - Avenida Reitor Miguel Calmon s/n - 40110-100 Salvador BA - Brasil. 
Posto que não está ainda estabelecida a forma como o vírus desencadeia a agressão ao sistema nervoso e que existe grande pleomorfismo da sua manifestação, chamamos a atenção para que HAM é uma doença sistêmica e que cabe ao neurologista procurar estabelecer o grau de acometimento sistêmico do paciente para, compreendendo a doença e suas manifestações, buscar a mais apropriada forma de tratamento.

\section{REFERÊNCIAS}

1. Gessain A, Vernant JC, Maurs L, Barin F, Gout O, Calender A, De Thé G. Antibodies to human T-lymphotropic virus type 1 in patients with tropical spastic paraparesis. Lancet 1985, 2: 407-410.

2. Gessain A, Gout O. Chronic myelopathy associated with human T-lymphotropic virus type I (HTLV-I). Ann Intern Med 1992, 117: 933-946.

3. Kuroda Y, Fukuoka M, Endo C, Matsui M, Kurohara K, Kakigi R, Tokunaga O. Occurrence of primary biliary cirrhosis, CREST syndrome and Sjogren's in a patient with HTLV-I associated myelopathy. J Neurol Sci 1993, 116: 47-51.

4. Lessa I, Moura L, Moraes D, Rios S, Melo A. HTLV-I and myelopathy in Salvador (Northeastern Brazil): a case control study. Arq Neuropsiquiatr 1993, 51: 447-451.

5. Mattos K, Queiroz C, Peçanha-Martins AC, Publio L, Vinhas V, Melo A. Lymphocyte alveolitis in HAM/TSP patients: preliminary report. Arq Neuropsiquiatr 1993, 51: 134-136.

6. Meireles A, Moreira ED Jr, Moreno-Carvalho OA, Badaró R, Melo A. HTLV-I associated myelopathy in Salvador (Northeastern Brazil). Arq Neuropsiquiatr 1992, 50: 189-190.

7. Melo A, Moura L, Rios S, Machado M, Costa G. Magnetic resonance imaging in HTLV-I associated myelopathy. Arq Neuropsiquiatr 1993, 51: 329-332.

8. Ogata A, Nagashima K, Tashiro K, Miyakawa A, Mikumi C. MRI pathological correlate of brain lesions in a necropsy case of HTLV-I associated myelopathy.

9. Osame M, Igata A, Matsumoto M, Kohka M, Usuku K, Izumo S. HTLV-I associated myelopathy (HAM): treatment trials, retrospective survey and clinical and laboratory findings. Hematol Rev 1990, 3: 271-284.

10. Roman GC, Schonberg BS, Madden DL, Sever JL, Hugon J, Ludolph A, Spencer PS. Human T-lymphotropic virus type 1 antibodies in serum of patients with tropical spastic paraparesis in the Seychelles. Arch Neurol 1987, 44: 605-607.

11. Yokota T, Yamada M, Furukawa T, Tsukagoshi H. HTLV-I associated meningitis. J Neurol 1988, 235: $129-130$.

12. Smith D, Lucas S, Jacewicz M. Multiple cerebral hemorrhages in HTLV-I associated myelopathy. Neurology 1993, 43: 412-414.

13. Spina-França A, Salum PNB, Limongi JCP, Berger A, Losso ER. Mielopatias: aspectos diagnósticos. Arq Neuropsiquiatr 1980, 38: 360-366.

14. Spina-França A, Livramento JA, Machado LR, Gomes HR, Vianna LS, Castro LHM, Nobrega JPS, Bacheschi LA. HTLV-I antibodies in serum and cerebrospinal fluid in tropical spastic paraparesis in Brasil. Arq Neuropsiquiatr 1990, 48: 441-447.

15. Uchiyama T, Yodoi J, Sagawa K, Takatsuki K, Uchino H. Adult T-cell leukemia: clinical and hematological features of 16 cases. Blood 1977, 50: 481-491. 